\title{
Root bacterial endophytes alter plant phenotype, but not physiology
}

\author{
Jeremiah A Henning ${ }^{\text {Corresp.. }}{ }^{1}$, David J Weston ${ }^{2}$, Dale A Pelletier ${ }^{2}$, Collin M Timm ${ }^{3}$, Sara S Jawdy ${ }^{2}$, Aimée T \\ Classen ${ }^{1,4}$ \\ 1 Department of Ecology \& Evolutionary Biology, University of Tennessee - Knoxville, Knoxville, Tennessee, United States \\ 2 Biosciences Division, Oak Ridge National Laboratory, Oak Ridge, TN, United States \\ 3 Joint Institute for Biological Sciences, University of Tennessee, Oak Ridge, TN, United States \\ 4 The Natural History Museum of Denmark, University of Copenhagen, Copenhagen, Denmark \\ Corresponding Author: Jeremiah A Henning \\ Email address: jhennin2@vols.utk.edu
}

Plant traits, such as root and leaf area, influence how plants interact with their environment and the diverse, microbiota living within plants can influence plant morphology and physiology. Here, we explored how three bacterial strains isolated from the Populus root microbiome, influenced plant phenotype. We chose three bacterial strains that differed in predicted metabolic capabilities, plant hormone production and metabolism, and secondary metabolite synthesis. We inoculated each bacterial strain on a single genotype of Populus trichocarpa and measured the response of plant growth related traits (root:shoot, biomass production, root and leaf growth rates) and physiological traits (chlorophyll content, net photosynthesis, net photosynthesis at saturating light - $A_{\text {sat }}$ and saturating $\mathrm{CO}_{2}-\mathrm{A}_{\max }$ ). Overall, we found that bacterial root endophyte infection increased root growth rate up to $184 \%$ and leaf growth rate up to $137 \%$ relative to non-inoculated control plants, evidence that plants respond to bacteria by modifying morphology. However, endophyte inoculation had no influence on total plant biomass and photosynthetic traits (net photosynthesis, chlorophyll content). In sum, bacterial inoculation did not significantly increase plant carbon fixation and biomass, but their presence altered where and how carbon was being allocated in the plant host. 
1 Title page

2

Root bacterial endophytes alter plant phenotype, but not physiology

3

4

5

6 Jeremiah A. Henning ${ }^{1}$, David J. Weston ${ }^{2}$, Dale A. Pelletier ${ }^{2}$, Collin M. Timm ${ }^{3}$, Sara S. Jawdy ${ }^{2}$,

7 Aimée T. Classen ${ }^{1,4}$

8

$9{ }^{1}$ Ecology \& Evolutionary Biology, The University of Tennessee, Knoxville, TN USA

102 Biosciences Division, Oak Ridge National Laboratory, Oak Ridge, TN USA

$11{ }^{3}$ Joint Institute for Biological Sciences, University of Tennessee, Oak Ridge, TN USA

$12{ }^{4}$ The Natural History Museum of Denmark, The University of Copenhagen København Ø,

13 Denmark

14

15 Corresponding author:

16 Jeremiah A. Henning

17 jhennin2@vols.utk.edu

18

19 


\section{Abstract (193 words)}

21 Plant traits, such as root and leaf area, influence how plants interact with their environment and

22 the diverse, microbiota living within plants can influence plant morphology and physiology.

23 Here, we explored how three bacterial strains isolated from the Populus root microbiome,

24 influenced plant phenotype. We chose three bacterial strains that differed in predicted metabolic

25 capabilities, plant hormone production and metabolism, and secondary metabolite synthesis. We

26 inoculated each bacterial strain on a single genotype of Populus trichocarpa and measured the

27 response of plant growth related traits (root:shoot, biomass production, root and leaf growth

28 rates) and physiological traits (chlorophyll content, net photosynthesis, net photosynthesis at

29 saturating light $-\mathrm{A}_{\text {sat }}$, and saturating $\left.\mathrm{CO}_{2}-\mathrm{A}_{\max }\right)$. Overall, we found that bacterial root endophyte

30 infection increased root growth rate up to $184 \%$ and leaf growth rate up to $137 \%$ relative to non-

31 inoculated control plants, evidence that plants respond to bacteria by modifying morphology.

32 However, endophyte inoculation had no influence on total plant biomass and photosynthetic

33 traits (net photosynthesis, chlorophyll content). In sum, bacterial inoculation did not significantly

34 increase plant carbon fixation and biomass, but their presence altered where and how carbon was 35 being allocated in the plant host. 


\section{Introduction}

38 A recent review exploring microbiome-mediated plant traits found that plant-associated microbes can modify fourteen out of thirty commonly measured functional traits (Cornelissen et al., 2003;

40

Friesen et al., 2011). For example, inoculation with common root-colonizing bacterial strains influenced root and leaf architectural traits, such as specific leaf area and specific root length, as well as plant physiological traits such as carbon fixation and chlorophyll content (Harris, Pacovsky, \& Paul, 1985; Ma et al., 2003; Friesen, 2013). Further, inoculation by different members of the plant microbiome may differentially alter plant phenotype (Zamioudis et al., 2013; Timm et al., 2016). The presence of unique bacterial strains in legume genotypes explained more variation in shoot biomass, root biomass, and plant height than plant genotype did (Tan \& Tan, 1986). Inoculation of common endophytes can also inhibit primary root elongation and promote lateral root formation and root hair production (Zamioudis et al., 2013; Weston et al., 2012). Recent breakthroughs in the multitude of the -omics fields have allowed for unprecedented mechanistic investigations of microbe-induced changes in host function (Verhagen et al., 2004; Walker et al., 2011; Weston et al., 2012; Vandenkoornhuyse et al., 2015; Timm et al., 2015; 2016) and have been the subject of multiple recent reviews (Friesen et al., 2011; Friesen, 2013; Vandenkoornhuyse et al., 2015; Hacquard \& Schadt, 2015; Lebeis, 2015; and many others). This work demonstrated that plant growth promoting bacteria elicit numerous changes in host gene expression through multiple and simultaneous hormonal and immune response pathways (Verhagen et al., 2004; Walker et al., 2011; Weston et al., 2012; Drogue et al., 2014; Timm et al., 2016). However, these studies fall short in explaining how changes in gene expression influence the overall plant phenotype or plant function. Thus, understanding the response of plant traits and overall plant phenotype to microbial strains remains a research gap. 
Here, we inoculated three endophytic bacterial strains (Pseudomonas fluorescens GM41,

61 Pseudomonas fluorescens GM30, and Burkholderia sp. BT03), originally isolated from wild

62 Populus, on a single genotype of Populus trichocarpa and measured plant phenotypic response

63 to bacterial inoculation. We measured a suite of traits commonly measured in the functional trait

64 ecology literature to explore how phenotype is influenced by bacterial strains within the pre-

65 existing functional trait framework. Plant functional trait ecology has largely ignored

66 microbiome contribution to plant phenotype. Bacterial strains belonging to the Pseudomonas

67 fluorescens group are common plant growth promoting bacteria that are abundant in the Populus

68 microbiome (see Gottel et al., 2011). Pseudomonas fluorescens accounted for approximately

$6934 \%$ of the sequences found in the Populus endosphere, but only $2-3 \%$ of the sequences in the

70 rhizosphere and soil samples originating from the same roots (Gottel et al., 2011). Pseudomonas

71 strains can alter plant host function by modifying plant growth (Kloepper et al., 1980;

72 Lugtenberg \& Kamilova, 2009; Timm et al., 2015), nutrient allocation (Bisht et al., 2009),

73 hormone signaling (Stearns et al., 2012), up-regulating/down-regulating of gene expression

74 pathways (Timm et al., 2016), and immune function (Verhagen et al., 2004; Weston et al., 2012).

75 Additionally, the Pseudomonas fluorescens clade has a large amount of functional diversity (Jun

76 et al., 2016), thus selecting two Pseudomonas strains allows us to explore how plant traits and

77 overall phenotype respond to closely related bacterial strain genomes. To contrast with these two

78 strains, we selected a distantly related, but enriched in Populus endosphere (Gottel et al., 2011),

79 bacterial strain from the genus Burkholderia.

80 We predicted that aboveground and belowground traits of Populus trichocarpa would

81 respond to Burkholderia and Pseudomonas strains and inoculation of different bacterial strains

82 would result in different plant phenotypes. Further, we predicted that the two Pseudomonas 
83 strains would produce a plant phenotype that was more similar to one another than to

84 Burkholderia because of phylogenetic relatedness, i.e. more shared functionality. To test our

85 predictions, we first conducted a genomic comparison using COG (clusters of orthologous

86 groups) database to predict the functional differences among strains. Next, we inoculated each

87 bacterial strain on Populus trichocarpa and measured a suite of physiological and architectural

88 plant traits including the root:shoot, biomass production, root and leaf growth rates, chlorophyll

89 content, net photosynthesis, and net photosynthesis at saturating light - $\mathrm{A}_{\text {sat }}$, and saturating $\mathrm{CO}_{2}$ -

$90 \mathrm{~A}_{\max }$. We chose to measure overall trait response to bacterial endophytes without measuring the

91 pathways involved because we were interested in understanding down-stream consequences of

92 bacterial inoculation on overall plant phenotype.

93

94 Materials and Methods

95 Populus trichocarpa genotype “93-968” (Labbe et al., 2014) was propagated in tissue culture

96 following standard procedures (see Kang et al., 2009). Briefly, in vitro cultures were established

97 from actively growing shoot tips collected from greenhouse-grown Populus plants. We sterilized

98 shoot tips by soaking fresh cut tips in a $1 \%$ Tween 20 solution for $5 \mathrm{~min}, 70 \%$ Ethanol solution

99 for $1 \mathrm{~min}$, a $0.525 \%$ sodium hypochlorite solution for $15 \mathrm{~min}$ and then rinsed them three times in

100 sterile $\mathrm{H}_{2} \mathrm{O}$ for $5 \mathrm{~min}$. Shoot tips were trimmed to $2 \mathrm{~cm}$ in length and transferred to a magenta

101 box (Sigma-Aldrich, St. Louis, MO) containing $80 \mathrm{~mL}$ of tissue media $(1 \times$ Murashige \& Skoog

102 (MS) basal medium (Murashige \& Skoog, 1962) supplemented with MS vitamins (Caisson Labs,

103 North Logan, UT, USA), 0.05\% 2-( $N$-morpholino) ethanesulfonic acid (MES hydrate) (Sigma-

104 Aldrich, St. Louis, MO, USA), 3\% sucrose, 0.1\% PPM ${ }^{\mathrm{TM}}$ (plant protective mixture) (Plant Cell

105 Technology, Washington, DC, USA), 0.5\% activated charcoal (Sigma-Aldrich, St. Louis, MO, 
106 USA), and 0.15\% Gelzan (Plantmedia, bioWORLD, Dublin, OH, USA). Plants were sub-

107 cultured until it was determined, using microscopy and colony formation units with R2A

108 medium, that the plants were axenic.

109 Plant cultures were rooted in a growth room at $25^{\circ} \mathrm{C}$ under a $16 \mathrm{~h}$ photoperiod. After root

110 establishment, plants that were similar in size and developmental stage were selected for

111 experimentation. Plants were weighed and scanned to account for initial plant size differences

112 among treatments. To ensure sterility during scanning, plants were placed between two $(21.59 \mathrm{x}$

$11327.94 \mathrm{~cm}$ ) sheets of cellulose acetate that were sprayed with $100 \%$ ethanol. Scans were

114 performed with a portable scanner (VuPoint Solutions Inc., City of Industry, CA, USA) at $600 \times$

115600 dpi. Scanned images were analyzed in WinRhizo (Regent Instruments, Quebec City,

116 Canada) to determine initial root surface area, root length, stem length, and leaf surface area.

117 After scanning, plants were transferred into experimental microcosms.

118

119 Experimental design

120 We constructed closed microcosms by interlocking two sterile Magenta boxes (Sigma-Aldrich,

121 St. Louis, MO, USA) with a coupler (Sigma-Aldrich, St. Louis, MO, USA). We added $150 \mathrm{ml}$

122 calcined clay (Pro's choice Sports Field Products, Chicago, IL, USA) and $70 \mathrm{ml}$ of $1 \times$

123 Hoagland's nutrient solution (Sigma-Aldrich, St. Louis, MO, USA) to each microcosm. We

124 drilled two $7 \mathrm{~mm}$ holes on adjacent sides of the upper magenta box and covered the holes with

125 adhesive microfiltration discs (Tissue Quick Plant Laboratories, Hampshire, United Kingdom) to

126 allow air to flow into and out of the microcosms and to prevent outside microbial contamination.

127 Prior to microbial addition, we double sterilized each closed microcosm by autoclaving on a 60

$128 \mathrm{~m}$ dry cycle on consecutive days. Pseudomonas fluorescens strains (GM30 and GM41) and 
129 Burkholderia sp. (BT03), hereafter termed Pseudomonas GM30, Pseudomonas GM41, and

130 Burkholderia BT03 were isolated from Populus deltoides endospheres from east Tennessee and

131 western North Carolina, USA (originally described in Brown et al., 2012). For full isolate

132 descriptions, see Brown et al., 2012; Weston et al., 2012; Utturkar et al., 2014; Timm et al.,

$1332015 ; 2016$. We selected these three strains because previous work (Pseudomonas GM30 -

134 Weston et al., 2012, Labbe et al., 2014; Pseudomonas GM41 - Labbe et al., 2014, Timm et al., 135 2016; Burkholderia Bt03 - Timm et al., 2016) had given us indication that strains were able to

136 influence traits in Arabidopsis thaliana (Weston et al., 2012), were able to manipulate plant gene

137 expression and hormonal signaling in P. deltoides (Timm et al., 2015; 2016), and were able to

138 influence host interactions with mycorrhizal symbionts (Labbe et al., 2014). Although strains

139 were isolated from $P$. deltoides, strains from Pseudomonas and Burkholderia readily colonize

140 natural P. trichocarpa tissues (Moore et al., 2006; Xin et al., 2009; Knoth et al., 2014; Kahn et

141 al., 2014; Doty et al., 2016). We grew bacterial strains in isolation and at a constant temperature,

$14225^{\circ} \mathrm{C}$, in $5 \mathrm{ml}$ of R2A medium. After growing overnight they were pelleted and re-suspended in

143 sterile water to an OD600 of $0.01\left(\sim 1.0 \times \mathrm{E} 7\right.$ cells $\left.\mathrm{ml}^{-1}\right)$.

144 We inoculated each microcosm by adding $10 \mathrm{ml}$ of the bacterial strain $\left(10^{7}\right.$ cells $\left.\mathrm{ml}^{-1}\right)$ to

145 the calcined clay substrate and stirring for $30 \mathrm{~s}$ to distribute the bacteria. After inoculation, we

146 planted the Populus clones within each microcosm. Each Populus was grown in an individual

147 microcosm in combination with one of the bacterial strains. Thus, the experiment had four

148 treatment combinations - Pseudomonas GM30 inoculation, Pseudomonas GM41 inoculation,

149 Burkholderia BT03 inoculation, and a bacteria-free control. In total, there were 32 microcosms

150 with four treatments $(\mathrm{n}=8)$. The experiment was divided into three different establishment dates

151 in 2014 (1 March, 3 replicated blocks; 25 March, 2 replicated blocks; and 2 April, 3 replicated 
152 blocks) because microbiome-free plant tissues were difficult to propagate. Plant-bacteria

153 combinations were grown in the microcosms for five weeks with a $16 \mathrm{hr}$ photoperiod, at $21^{\circ} \mathrm{C}$

154 and $80 \%$ relative humidity.

155 After 35 days of growth, plants were removed from microcosms, submerged in sterilized

156 deionized $\mathrm{H}_{2} \mathrm{O}$ to remove clay from the root system, weighed, and scanned. Scans were analyzed

157 with WinRhizo to determine final root surface area, total root length, stem length, and leaf

158 surface area. For each plant, the final measurement of root surface area, total root length, stem

159 length, and leaf surface area was subtracted from the initial measurement and divided by the

160 experiment duration to determine tissue growth rates $\left(\mathrm{cm} \mathrm{d}^{-1} \mathrm{or} \mathrm{cm}^{2} \mathrm{~d}^{-1}\right)$. Additionally, each plant

161 was dried for 48 hours at $70^{\circ} \mathrm{C}$ and weighed to measure leaf, shoot (leaf + stem) and root and

162 total dry mass. Specific leaf area and the specific root length of each individual were calculated

163 by dividing leaf area by leaf dry mass or by dividing root length by root dry mass, respectively.

164 To measure host physiological response to different bacterial strains, leaf gas-exchange

165 was measured and used to estimate leaf photosynthesis on our first replicate block (March 1, n =

166 3). For each plant, gas exchange of the largest leaf of the plant was measured (Li-Cor model

167 6400, Li-Cor Biosciences, Lincoln, Nebraska, USA) immediately prior to our experimental

168 harvest. The maximum rate of photosynthesis in saturating light under ambient $\mathrm{CO}_{2}\left(\mathrm{~A}_{\text {sat }}\right)$, the

169 maximum rate of photosynthesis in saturating light and saturating $\mathrm{CO}_{2}\left(\mathrm{~A}_{\max }\right)$, and the quantum

170 yield of $\mathrm{CO}_{2}$ fixation $(\Phi)$ were all measured. Finally, average leaf chlorophyll content was

171 measured on three fully opened leaves (Konica Minolta Chlorophyll Meter SPAD-S02, Ramsey,

172 NJ, USA).

173

174 Comparative genomics of microbes 
175 Genomes of Pseudomonas GM30 and GM41 and Burkholderia BT03 were sequenced at

176 Oak Ridge National Laboratory and genes were identified using Prodigal (Brown et al., 2012,

177 Utturkar et al., 2014) and are available at NCBI (GM41: AKJN00000000.2; GM30:

178 AKJP02000000.2; BT03: NZ_AKKD000000000.2). Genome annotation, genomes statistics, and 179 annotation comparisons were performed using IMG tools (img.jgi.doe.gov). Genome statistics 180 and COG functional predictions were extracted from Integrated Microbial Genomes

181 (img.jgi.doe.gov) and then they were compared manually for differential inclusion of predicted 182 functions.

183

184

\section{Bacterial Colonization}

186 To test for endophytic colonization of Pseudomonas GM41, Pseudomonas GM30, and

187 Burkholderia BT03, we planted cuttings of P. trichocarpa into a magenta box using similar

188 methodology and treatments described above $(n=3)$. After 2 weeks of growth, all the plant roots,

189 stems, and 1-2 mature leaves were surface sterilized by dipping them in a $\sim 10 \%$ bleach solution,

190 followed by $70 \%$ ethanol, and then rinsing in water three times. We recorded wet weight of plant

191 tissues and then separately macerated each plant tissue compartment in a sterile mortar and pestle

192 in $1 \mathrm{ml}$ sterile $1 \times$ PBS. We transferred macerated plant tissues to a 24 -well plate where we serial

193 diluted each sample by $10 \%$ with $1 \times$ PBS at $1 \times, 0.1 \times, 0.01 \times$ of original sample concentration.

194 Each sample was streaked onto R2A media plates and allowed to grow for 48 hours at $20^{\circ} \mathrm{C}$.

195 After 48 hours, colony formation was counted. We calculated CFU mg-1 of plant tissue by

196 multiplying colony number per plate by $10^{\text {(dilution factor +1) }}$ and then dividing that number by the

197 dry tissue mass $\left(\mathrm{mg}^{1}\right)$. 


\section{Statistical analyses}

199 We tested all data for normality using the normalTest function in the fBasics package (version 2003011.87 , R metrics core team 2014) for R version 3.0.2 ( $\mathrm{R}$ development core team, 2013) and 201 RStudio version 0.98.495 (RStudio, 2013). If data were not normally distributed, we performed $202 \log$ transformations or square-root transformations to satisfy the normality assumptions of 203 ANOVA.

To explore plant trait response (root dry mass, leaf dry mass, shoot dry mass, total dry mass, root: shoot, root growth rates, leaf growth rates, change in leaf number, specific root length, specific leaf area) to bacterial strains, we used linear mixed-effect models using the lme4 package in R (Bates et al., 2014). Bacterial strain was a fixed effect in the model and experimental block (three establishment dates) was a random factor. For plant dry mass measures, we incorporated initial measurements of root surface area in the root dry mass model and initial leaf surface area in the aboveground dry mass model as covariates. To test for

211 significance of bacterial strain (fixed effects) and covariate (initial growth measure) we 212 performed a likelihood ratio test to compare models with and without fixed effects and 213 covariates. If including fixed factors (bacterial strain) was significant an improvement to model 214 fit ( $\mathrm{p}$ value $<0.05$ in likelihood ratio test), we calculated least square means and confidence 215 intervals using the difflsmeans function to calculate differences among strains using the lmerTest 216 package version 2.0-3 (Kuznetsova, Brockhoff, \& Christensen, 2014). We measured host 217 response to bacterial inoculation by calculating the percent change in trait values ((mean trait 218 value for Populus inoculated with bacterial strain - mean non-inoculated trait value) $\times 100$ ). To test physiological responses (carboxylase activity, $\mathrm{A}_{\max }, \mathrm{A}_{\mathrm{sat}}$ ) of plant hosts to

220 bacterial inoculation, we used one-way analysis of variance (ANOVA) using the Anova function 
221 in the CAR package, (version 2.0-22, Fox \& Weisberg 2011) because we collected physiology

222 data on only a single sampling date $(\mathrm{n}=3)$. All raw data and $\mathrm{R}$ code is available in Supplemental

223 Table 2 and 3 , respectively.

224

\section{Results}

226 Bacterial strains differ in genomic content

227 We compared the genomes of Burkholderia BT03 and Pseudomonas GM30 and GM41 based on 228 predicted enzyme functions using the COG database (Table 1). Overall, our genome comparison 229 demonstrated that the bacterial strains differed in genome size and functional gene content. 230 Burkholderia BT03 had a relatively large genome (10.9 Mb) compared to Pseudomonas GM30 231 (6.1 Mb) and Pseudomonas GM41 (6.6 Mb) (Table 1). We found all three bacterial strains 232 shared functions that were likely critical for establishment and survival in the plant microbiome 233 including the production of the plant hormone auxin, pili, flagella, chemotaxis, increased signal 234 transduction, and secretion systems. However, we found many functional differences among our 235 strains. The genome of Burkholderia encoded multiple pathways predicted to be involved in the 236 metabolism of the plant hormones, salicylate and ethylene (Table 1). Relative to the

237 Pseudomonas genomes, the Burkholderia genome encoded for numerous secondary metabolite

238 biosynthesis pathways and more carbohydrate and lipid transporters, suggesting increased 239 metabolic capabilities within Burkholderia (Table 1).

240 Even through Pseudomonas GM30 and Pseudomonas GM41 were classified as the same

241 16S OTU, their genome size differed as did the predicted functional capabilities of the two

242 strains. The genome of Pseudomonas GM41 encoded for phosphorus solubilization and nitrate

243 reduction, which were lacking in the Pseudomonas GM30 genome. Additionally, Pseudomonas 
244 GM41 contained more secondary metabolite biosynthesis elements compared to Pseudomonas

245 GM30. We also found that the genome of Pseudomonas GM41 contained more genes coding for

246 carbohydrate metabolism, lipid metabolism, and amino acid transport and metabolism, energy

247 production and conversion, suggesting that Pseudomonas GM41 may contain more metabolic

248 breadth than Pseudomonas GM30 (Table 1). Taken together, our results demonstrated that these

249 three bacterial strains differ in genome size and their functional gene content.

250

\section{Bacterial colonization of Populus root tissue}

252 All three of the bacterial strains colonized Populus hosts. Colony-forming units were enriched in 253 all three bacterial strains relative to the control in the $0.1 \times$ and $0.01 \times$ dilutions $(0.1 \times$ dilution $F=$ $25418.77, p<0.0001 ; 0.01 \times$ dilution $F=13.78, p<0.0001$, Table 2), although CFU number was 255 variable across dilutions, tissue types, and bacterial strain. However, we found no difference in 256 CFUs among non-inoculated control and Pseudomonas GM30, GM41, and Burkholderia BT03 257 inoculated host plants at the $1 \times$ dilution $(F=1.24, p=0.319$ Table 2$)$. Across nearly all tissue 258 types, we found that Pseudomonas GM30, Pseudomonas GM41, and Burkholderia BT03 259 inoculated plants had 10-10000× more CFUs than did non-inoculated control plants (Table 2).

260 All three bacterial strains colonized leaf and stem tissues, but the highest CFUs across bacterial 261 treatments were consistently observed in roots (Table 2). Inoculated host plants contained 0$26228809015 \mathrm{CFU} \mathrm{mg}^{-1}$ in roots, $0-1166273 \mathrm{CFU} \mathrm{mg}^{-1}$ in stems, and 0-73537 CFU mg-1 in leaves

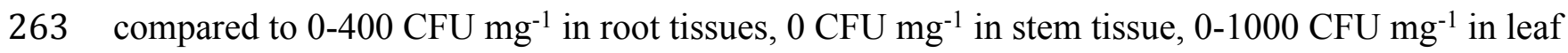
264 tissue compared to non-inoculated control plants (Table 2).

265

266 Plant structure is modified by bacterial inoculation 
267 Overall, we found that plant trait response to bacterial endophytes was strain specific.

268 Specifically, mean root growth rate increased 184\% with Pseudomonas GM30 colonization $(t=$

$2693.84, p=0.001)$, however root growth rates were unaffected by Pseudomonas GM41 $(t=1.61, p$ $270=0.12)$, and Burkholderia BT03 $(t=1.18, p=0.25)$ inoculation (Fig 1, Supplemental Table 1).

271 Similarly, mean leaf growth rate increased $114 \%$ and $138 \%$ with Pseudomonas GM30 $(t=2.27$, $272 p=0.03)$ and Pseudomonas GM41 $(t=2.86, p=0.01)$ inoculation, but leaf growth rate was 273 unaffected by Burkholderia inoculation $(t=1.02, p=0.32)$ (Fig 1, Supplemental Table 1).

274 Inoculation by Pseudomonas GM30 increased leaf number by $36 \%(t=3.34, p=0.003)$ but leaf 275 number was unaffected by Pseudomonas GM41 $(t=0.93, p=0.36)$ and Burkholderia $\mathrm{BT} 03(t=$ $2761.418, p=0.17$ ) inoculation (Fig 1). We observed no differences in stem elongation with 277 bacterial inoculation (chisq=0.06, $p=0.97$, Supplemental Table 1). Interestingly, we observed no differences in total plant dry mass (chisq $=3.27, p=0.195$, 279 Fig 2), root dry mass (chisq $=0.00, p=1.00$, Fig 2$)$, root:shoot ratio (chisq $=0.00, p=1.00$, 280 Supplemental Table 1) or plant height $($ chisq $=1.99, p=0.158$ Supplemental Table 1) with 281 bacterial inoculation. However, Pseudomonas GM30 inoculation increased leaf dry biomass by $28286 \%(t=2.43, p=0.02)$ relative to control plants, however leaf biomass was unaffected by 283 Pseudomonas GM41 $(t=0.97, p=0.33)$ and Burkholderia BT03 $(t=1.70, p=0.10)($ Fig 2, 284 Supplemental Table 1). We observed no differences in specific leaf area with bacterial 285 inoculation (chisq $=2.60, p=0.46$, Supplemental Table 1). Thus, inoculation of Pseudomonas 286 GM30 increased leaf surface area $(t=2.27, p=0.03)$ and aboveground dry mass $(t=2.43, p=$ 287 0.02), without changing leaf area:mass ratios. We found no significant differences in root 288 length:dry mass (specific root length, chisq $=1.06, \mathrm{p}=0.79$ ) with bacterial inoculation 
289 (Supplemental Table 1). Our results indicate that bacterial strains modify plant resource

290 allocation but not total dry mass production.

291

292 Plant physiology is not affected by bacterial inoculation

293 Bacterial inoculation had no measureable effects on any physiological trait we measured:

294 chlorophyll content $(\mathrm{SPAD})(\mathrm{chisq}=2.15, \mathrm{p}=0.54)$, quantum yield of photosynthesis $(\phi)(F=$

$2951.01, p=0.43)$, net photosynthesis at saturating light conditions $\left(\mathrm{A}_{\text {sat }}\right)(F=0.76, p=0.55)$ or

296 maximum net photosynthesis at saturating light and $\left[\mathrm{CO}_{2}\right]\left(\mathrm{A}_{\max }\right)(F=1.98, p=0.19)(\mathrm{Fig} 3)$. In

297 agreement with the total dry mass data, we did not observe significant changes in the measured

298 photosynthetic parameters. Thus, changes in plant structure were not linked with increased

299 photosynthetic capacity, efficiency, or carbon assimilation rates.

300

301 Discussion

302 The plant root microbiome can have a strong influence on plant production and phenotype

303 (Friesen, 2013; Vandenkoornhuyse, et al., 2015); yet, less is known about how plant trait

304 expression, production, and physiology are influenced by individual endophytic strains. We

305 explored how plant morphological traits, productivity, and cellular physiology in Populus

306 trichocarpa responded to inoculation with three bacterial strains, two closely related

307 Pseudomonas fluorescens strains (GM30 \& GM41) and a more distantly related Burkholderia

308 strain (BT03). We selected bacterial strains that were predicted to differ in metabolic

309 capabilities, plant hormone production and metabolism, and secondary metabolite synthesis in an

310 effort to understand how plant phenotype is influenced by inoculation with different strains of

311 common endophytic bacteria (Table 1, Timm et al., 2015; 2016). Our comparative genomic 
312 analysis revealed that while all three strains share many common endophytic functions like plant

313 hormone signal disruption, production of plant hormone auxin, pili, flagella, and chemotaxis,

314 strains potentially differed in their ability to perform these functions. Overall, we found that

315 Burkholderia and Pseudomonas genomes differed in the carbon substrates they were predicted to

316 degrade, plant hormone production and metabolism, and secondary metabolite synthesis, which

317 led us to predict that plant response to bacterial inoculation would lead to different phenotypes

318 between treatments. All three strains could colonize Populus roots, leaves, and stems, however

319 CFU number was highest within root tissues in all three strains (Table 2).

320 Overall, we found root endophyte inoculation altered plant resource allocation patterns

321 without influencing total plant biomass accumulation (Fig 1). Additionally, we found that plant

322 trait response and overall phenotype differed across bacterial strains in ways that would not have

323 been predicted from our genome analysis. Specifically, Burkholderia BT03 was predicted to

324 produce auxin and to metabolize salicylate and ethylene, three plant hormones crucial to plant

325 growth and development (see Yang \& Hoffman, 1984; Wasternack \& Parthier, 1997; Chen et al.,

326 2009; Dempsey et al., 2011). Additionally, we found the Burkholderia genome encoded for

327 multiple transposase elements that degrade poplar-produced aromatics and metabolites (Timm et

328 al., 2015; 2016). Despite the predicted ability of Burkholderia to manipulate multiple plant

329 hormonal and signaling pathways, we observed no measurable changes in any traits when

330 Populus was inoculated with Burkholderia (Figs 1, 2, 3). This was especially surprising since we

331 consistently measured the highest CFU abundance within Burkholderia inoculated individuals

332 (Table 2).

333 In spite of close genetic relatedness and classification under the same 16S OTU profile,

334 our Pseudomonas strains differed in key functional capabilities. Specifically, Pseudomonas 
335 GM41 encoded for phosphate solubilization and denitrification ability, suggesting these two

336 strains may differentially influence host nutrition, although this remains untested. Our genome

337 analysis revealed that both strains were capable of producing the plant hormone auxin, however

338 another study found that Pseudomonas GM41 produced two times more auxin than

339 Pseudomonas GM30 (Timm et al., 2015). Auxin synthesis by endophytic bacteria can increase

340 root branching and lateral root formation and decrease overall plant height, leaf number,

341 chlorophyll content and photosynthetic efficiency (Romano, Cooper, \& Klee, 1993; Fu \&

342 Harberd, 2003; Weston et al., 2012). Thus, we predicted that Pseudomonas GM41 would have a

343 strong influence on plant root traits, however we observed no measurable effects of

344 Pseudomonas GM41 inoculation on root growth rate or morphology (Fig 1, Supplemental Table

345 1). Belowground, Pseudomonas GM30 inoculation increased root surface area growth rate by

346 184\% (Fig 1) without increasing root biomass (Fig 2), suggesting Pseudomonas GM30

347 inoculation may change root morphology, leading to longer, thinner, highly-branched roots with

348 similar biomass, as we predicted. Similar patterns have been observed when Pseudomonas

349 GM30 is inoculated on both Arabidopsis (Weston et al., 2012) and Populus deltoides (Timm et

350 al., 2015; 2016). Additionally, inoculation of Pseudomonas GM30 increased leaf surface area

351 growth rate by $114 \%$ (Fig 1), leaf number by 36\% (Fig 1), and aboveground biomass by $86 \%$

352 (Fig 2) but did not influence specific leaf area (Supplemental Table 1), whereas closely-related

353 Pseudomonas GM41 increased leaf surface area growth rate by 138\% (Fig 1) but did not change

354 leaf number (Fig 1) or aboveground biomass (Fig 2). Unlike Burkholderia, Pseudomonas

355 genomes do not contain the genes to directly metabolize salicylate, however inoculation of

356 Pseudomonas GM41 can up-regulate salicylic acid synthesis and degradation in Populus (Timm

357 et al., 2016). Taken together, our data suggest that predicting plant phenotypic response to 
358 bacterial inoculation, even in overly simplified systems using fully sequenced bacterial strains, is

359 extremely complex and difficult.

Contrary to our predictions, leaf physiology (Fig 3), plant height (Supplemental Table 1),

361 root:shoot (Supplemental table 1), specific leaf area (Supplemental table 1), specific root length

362 (Supplemental table 1), and total plant dry mass (Fig 2) were not influenced by bacterial

363 inoculation. It is possible that multiple, overlapping plant signaling and gene expression effects

364 induced by bacterial endophyte inoculation may mask a hosts' phenotype response. For example,

365 endophytes simultaneously up- and down-regulate numerous genes and metabolites in plant

366 tissue (see Verhagen et al., 2004; Wang et al., 2005; Walker et al., 2011; Weston et al., 2012;

367 Timm et al., 2016). Thus, counteracting influences among different gene pathways may conceal

368 plant responses to endophyte inoculation when measuring down-stream phenotype and

369 functional traits (Bashan, Holguin, \& de-Bashan 2004; Timm et al., 2016). Additionally, host

370 physiological response to endophyte inoculation may vary with bacterial strain (Kandasamy et

371 al., 2009; Weston et al., 2012; Timm et al., 2016), plant host (Smith and Goodman 1999), plant

372 ontogeny (Siddiqui \& Shaukat 2003), or plant stress (Dimkpa, Weinand, \& Asch 2009; Yang,

373 Kloepper, \& Ryu 2009; Lau \& Lennon 2012). For example, Root colonization by Pseudomonas

374 can reduce chlorophyll content and net photosynthesis $\left(\mathrm{A}_{\mathrm{sat}}\right)$ in a variety of plant hosts (Zou et

375 al., 2005; Weston et al., 2012). However Pseudomonas colonization can also increase

376 photosynthetic activity and chlorophyll content (Kandasamy et al., 2009, Timm et al., 2016).

377 Thus, biotic and abiotic contexts may drive the phenotypic response of hosts to endophyte

378 inoculation, however this idea requires further testing.

379 Our study focused on the response of plant functional traits to monoculture associations

380 of common endosphere bacteria, however future studies should focus on exploring how plant 
381 phenotype responds to diverse microbiome communities. With a few well-known exceptions

382 (Tan \& Tan 1986; Harris, Pacovsky, \& Paul 1985; Ma et al., 2003, Lau \& Lennon 2011; 2012),

383 bacterial community composition in roots has been ignored in studies exploring what drives

384 natural variation in plant traits (Friesen et al., 2011; Friesen 2013; Timm et al., 2016). We

385 propose a multifaceted approach to investigate linkages among the plant microbiome and natural

386 plant trait variation. First, incorporation of microbiome composition into studies that currently

387 investigate host identity/genotype and environmental parameters may be important for finding

388 patterns in natural trait variation - especially when conduced across a variety of environmental

389 gradients. Second, once correlations between microbiomes and plant traits are observed in the

390 field, detailed work constructing communities in the lab and greenhouse would enable a

391 mechanistic understanding of what is underlying the observed patterns. These studies could be

392 especially fruitful when conducted across natural biotic and abiotic environmental gradients in

393 the laboratory, greenhouse, and field settings (Classen et al., 2015).

394

\section{Conclusions}

396 Our study demonstrates that bacteria living in plant roots can influence plant morphological

397 traits. Increasingly, ecologists are using plant functional traits to explore how changing

398 environments might alter plant function (Wright et al., 2004; Reich 2014). Plant traits, such as

399 specific leaf area and specific root length, are often significantly correlated with important plant

400 functions such as carbon fixation and nutrient uptake (Diaz \& Cabido 2001). Researchers are

401 using correlations between plant traits and function to extrapolate how plants and ecosystems

402 will respond to global changes (Reich et al., 1999; Wright et al., 2004; Reich 2014). While

403 interactions between plant genotype and environment undoubtedly influence plant phenotypic 
404 plasticity (Bradshaw 1965; Schlichting 1986; Sultan 2000; Des Marais, Hernandez, \& Juenger 405 2013), phenotype is also heavily influenced by biotic factors, like the microbiome bacterial 406 endophytes (Lau \& Lennon 2011; 2012; Wagner et al., 2014; Hacquard \& Schadt 2015). Given 407 that plant-microbial studies, including ours, have observed strong linkages between microbiome 408 and plant phenotype (reviewed in Friesen et al., 2011; Friesen 2013) interactions among global 409 change drivers, plant genotypes, and plant microbiomes, should be considered in trait-based 410 approaches to ecological questions (Classen et al., 2015).

411

\section{Acknowledgements}

413 We thank Lee Gunter, Tse-Yuan Lu, Kelsey Carter, Jesse Labbe, and W. Nathan Cude for their 414 assistance in data collection and plant propagation. The Classen Ecosystem Ecology group and 415 three reviewers provided valuable input on earlier reviews of this manuscript. 


\section{References}

419 Bashan Y, Holguin G, de-Bashan LE. 2004. Azospirillum-plant relationships: physiological,

420 molecular, agricultural, and environmental advances (1997-2003). Canadian Journal of

421 Microbiology. 50:521-577.

422 Bates D, Maechler M, Bolker B, Walker S. 2015. Fitting Linear Mixed-Effects Models Using 423 Ime4. Journal of Statistical Software. 67:1-48.

424 Bisht R, Chaturvedi S, Srivastava R, Sharma A, Johri B. 2009. Effect of arbuscular mycorrhizal 425 fungi, Pseudomonas fluorescens and Rhizobium leguminosarum on the growth and nutrient 426 status of Dalbergia sissoo Roxb. Tropical Ecology. 50:231.

427 Bradshaw AD. 1965. Evolutionary significance of phenotypic plasticity in plants. Advances in $428 \quad$ Genetics. 13:115-155.

429 Brown SD, Utturkar SM, Klingeman DM, Johnson CM, Martin SL, Land ML, Lu TYS, Schadt 430 CW, Doktycz MJ, Pelletier DA. 2012. Twenty-one genome sequences from Pseudomonas 431 species and 19 genome sequences from diverse bacteria isolated from the rhizosphere and 432 endosphere of Populus deltoides. Journal of Bacteriology. 194:5991-5993.

433 Chen Z, Zheng Z, Huang J, Lai Z, Fan B. 2009. Biosynthesis of salicylic acid in plants. Plant $434 \quad$ Signaling \& Behavior. 4:493-496.

435 Classen AT, Sundqvist M, Henning JA, Newman GS, Moore JAM, Cregger M, Moorhead LC, 436 Patterson CM. 2015. Direct and indirect effects of climate change on soil microbial and soil 437 microbial-plant interactions: What lies ahead? Ecosphere. 6(8):130. doi: 10.1890/ES15$438 \quad 00217.1$.

439 Cornelissen JHC, Lavorel S, Garnier E, Diaz S, Buchmann N, Gurvich DE, Reich PB, ter Steege 440 H, Morgan HD, van der Heijden MGA, Pausas JG, Poorter H. 2003. A handbook of protocols 
441 for standardised and easy measurement of plant functional traits worldwide. Australian

$442 \quad$ Journal of Botany. 51:335-380.

443 Dempsey DMA, Vlot AC, Wildermuth MC, and Klessig DF. 2011. Salicylic Acid Biosynthesis 444 and Metabolism. The Arabidopsis Book. 9: e0156 doi: 10.1199/tab.0156.

445 Des Marais DL, Hernandez KM, Juenger TE. 2013. Genotype-by-environment interaction and 446 plasticity: exploring genomic responses of plants to the abiotic environment. Annual Review 447 of Ecology, Evolution, and Systematics. 44:5-29.

448 Díaz S, Cabido M. 2001. Vive la différence: plant functional diversity matters to ecosystem 449 processes. Trends in Ecology \& Evolution. 16:646-655.

450 Dimkpa C, Weinand T, Asch F. 2009. Plant-rhizobacteria interactions alleviate abiotic stress $451 \quad$ conditions. Plant, cell \& Environment. 32:1682-1694.

452 Doty SL, Sher AW, Fleck ND, Khorasani M, Bumgarner RE, Khan Z, Ko AWK, Kim S-H, 453 DeLuca TH. 2016. Variable Nitrogen Fixation in Wild Populus. PLoS ONE. 454 doi:11:e0155979.

455 Drogue B, Sanguin H, Chamam A, Mozar M, Llauro C, Panaud O, Prigent-Combaret C, Picault 456 N, Wisniewski-Dyé F. 2014. Plant root transcriptome profiling reveals a strain-dependent 457 response during Azospirillum-rice cooperation. Frontiers in Plant Science. 5:607 458 doi:10.3389/fpls:2014.00607.

459 Fox J, Weisberg S. 2011. An $\{R\}$ Companion to Applied Regression, Second Edition. Thousand $460 \quad$ Oaks CA: Sage.

461 Friesen ML. 2013. Microbially Mediated plant functional traits molecular microbial ecology of 462 the rhizosphere. John Wiley and Sons, Inc., pp 87-102. 
463 Friesen ML, Porter SS, Stark SC, von Wettberg EJ, Sachs JL, Martinez-Romero E. 2011.

464 Microbially mediated plant functional traits. Annual Review of Ecology, Evolution, and

$465 \quad$ Systematics. 42:23-46.

466 Fu X, Harberd NP. 2003. Auxin promotes Arabidopsis root growth by modulating gibberellin

467 response. Nature. 421:740-743.

468 Gottel NR, Castro HF, Kerley M, Yang Z, Pelletier DA, Podar M, Karpinets T, Uberbacher E,

469 Tuskan GA, Vilgalys R, Doktycz MJ, Schadt CW. 2011. Distinct microbial communities

470 within the endosphere and rhizosphere of Populus deltoides roots across contrasting soil

471 types. Applied and Environmental Microbiology. 77:5934-5944.

472 Hacquard S, Schadt CW. 2015. Towards a holistic understanding of the beneficial interactions 473 across the Populus microbiome. New Phytologist. 205:1424-1430.

474 Harris D, Pacovsky RS, Paul EA. 1985. Carbon economy of soybean-Rhizobium-Glomus 475 associations. New Phytologist. 101:427.

476 Jun SR, Wassenaar TM, Nookaew I, Hauser L, Wanchai V, Land M, Timm CM, Lu TYS, Schadt

477 CW, Doktycz MJ, Pelletier DA, Ussery DW. 2016. Diversity of Pseudomonas Genomes, 478 Including Populus-Associated Isolates, as Revealed by Comparative Genome Analysis. 479 Applied and Environmental Microbiology. 82:375-383.

480 Kang B, Osburn L, Kopsell D, Tuskan G, Cheng ZM. 2009. Micropropagation of Populus 481 trichocarpa 'Nisqually-1': the genotype deriving the Populus reference genome. Plant Cell, $482 \quad$ Tissue and Organ Culture. 99:251-257.

483 Khan Z, Roman D, Kintz T, delas Alas M, Yap R, Doty S. 2014. Degradation, phytoprotection 484 and phytoremediation of phenanthrene by endophyte Pseudomonas putida, PD1.

$485 \quad$ Environmental science \& technology. 48:12221-12228. 
486 Kloepper JW, Leong J, Teintze M, Schroth MN. 1980 Enhanced plant growth by siderophores 487 produced by plant growth-promoting rhizobacteria. Nature. 286:885-886.

488 Knoth JL, Kim S-H, Ettl GJ, Doty SL. 2014. Biological nitrogen fixation and biomass

489 accumulation within poplar clones as a result of inoculations with diazotrophic endophyte $490 \quad$ consortia. New Phytologist. 201:599-609.

491 Kandasamy S, Loganathan K, Muthuraj R, Duraisamy S, Seetharaman S, Thiruvengadam R, 492 Ponnusamy B, Ramasamy S. 2009. Understanding the molecular basis of plant growth 493 promotional effect of Pseudomonas fluorescens on rice through protein profiling. Proteome $494 \quad$ Science 7:1-8.

495 Kuznetsova A, Brockhoff P, Christensen R. 2014. LmerTest: tests for random and fixed effects 496 for linear mixed effect models. R package, version 2.0-3.

497 Labbé JL, Weston DJ, Dunkirk N, Pelletier DA, Tuskan GA. 2014. Newly identified helper 498 bacteria stimulate ectomycorrhizal formation in Populus. Frontiers of Plant Science. 5:579 499 doi: 10.3389/fpls.2014.00579.

500 Lau JA, Lennon JT. 2011. Evolutionary ecology of plant-microbe interactions: soil microbial $501 \quad$ structure alters selection on plant traits. New Phytologist. 192:215-224.

502 Lau JA, Lennon JT. 2012. Rapid responses of soil microorganisms improve plant fitness in novel 503 environments. Proceedings of the National Academy of Sciences. 109:14058-62.

504 Lebeis SL. 2015. Greater than the sum of their parts: characterizing plant microbiomes at the 505 community-level. Current Opinion in Plant Biology. 24:82-86.

506 Lugtenberg B, Kamilova F. 2009. Plant-Growth-Promoting Rhizobacteria. Annual Review of 507 Microbiology. 63:541-556. 
508 Ma W, Sebestianova S, Sebestian J, Burd G, Guinel F, Glick B. 2003. Prevalence of 1-

509 aminocyclopropane-1-carboxylate deaminase in Rhizobium spp. Antonie van Leeuwenhoek.

$510 \quad 83: 285-291$.

511 Moore FP, Barac T, Borremans B, Oeyen L, Vangronsveld J, van der Lelie D, Campbell CD,

512 Moore ERB. 2006. Endophytic bacterial diversity in poplar trees growing on a BTEX-

513 contaminated site: The characterisation of isolates with potential to enhance

514 phytoremediation. Systematic and Applied Microbiology. 29:539-556.

515 Murashige T, Skoog F. 1962. A revised medium for rapid growth and bio assays with tobacco

516 tissue cultures. Physiologia Plantarum. 15:473-497.

517 Reich PB. 2014. The world-wide 'fast-slow' plant economics spectrum: a traits manifesto.

$518 \quad$ Journal of Ecology. 102:275-301.

519 Reich PB, Ellsworth DS, Walters MB, Vose JM, Gresham C, Volin JC, Bowman WD. 1999.

520 Generality of leaf trait relationships: a test across six biomes. Ecology. 80:1955-1969.

521 Romano CP, Cooper ML, Klee HJ. 1993. Uncoupling auxin and ethylene effects in transgenic

522 tobacco and arabidopsis plants. Plant Cell. 5:181-189.

523 Schlichting CD. 1986. The evolution of phenotypic plasticity in plants. Annual Review of

524 Ecology, Evolution, and Systematics. 17:667-693.

525 Siddiqui IA, Shaukat SS. 2003. Plant species, host age and host genotype effects on Meloidogyne

526 incognita biocontrol by Pseudomonas fluorescens strain CHA0 and its genetically-modified

527 derivatives. Journal of Phytopathology. 151:231-238.

528 Smith KP, Goodman RM. 1999. Host variation for interactions with beneficial plant-associated

529 microbes. Annual Review of Phytopathology. 37:473-491. 
530 Stearns JC, Woody OZ, McConkey BJ, Glick BR. 2012. Effects of bacterial ACC deaminase on

531 Brassica napus gene expression. Molecular Plant Microbe Interactions. 25:668-676 doi:

532 10.1094/MPMI-08-11-0213.

533 Sultan SE. 2000. Phenotypic plasticity for plant development, function and life history. Trends in $534 \quad$ Plant Science. 5:537-542.

535 Tan G, Tan W. 1986. Interaction between alfalfa cultivars and Rhizobium strains for nitrogen 536 fixation. Theoretical and Applied Genetics. 71:724-729.

537 Timm CM, Campbell AG, Utturkar, SM, Jun SR, Parales RE, Tan W, Robeson MS, Lu TYS, 538 Jawdy S, Brown SD, Ussery DW, Schadt CW, Tuskan GA, Doktycz MJ, Weston DJ, Pelletier

539 DA. 2015. Metabolic functions of Pseudomonas fluorescens strains from Populus deltoides 540 depend on rhizosphere or endosphere isolation compartment. Frontiers in Microbiology. 6 541 doi: $\underline{10.3389 / \text { fmicb.2015.01118. }}$.

542 Timm CM, Pelletier DA, Jawdy S, Gunter LE, Henning JA, Engle N, Aufrecht J, Gee E,

543 Nookaew I, Yang Z, Lu TYS, Tschaplinksi TJ, Doktycz MJ, Tuskan GA, Weston DJ. 2016.

544 Two poplar-associated bacterial isolates induce additive favorable responses in a constructed

545 plant-microbiome system. Frontiers in Plant Science. 7 doi: 10.3389/fpls.2016.00497.

546 Utturkar SM, Klingeman DM, Land ML, Schadt CW, Doktycz MJ, Pelletier DA, Brown SD.

547 2014. Evaluation and validation of de novo and hybrid assembly techniques to derive high548 quality genome sequences. Bioinformatics. 30:2709-2716.

549 Vandenkoornhuyse P, Quaiser A, Duhamel M, Le Van A, Dufresne A. 2015. The importance of 550 the microbiome of the plant holobiont. New Phytologist. 206:1196-1206. 
551 Verhagen BWM, Glazebrook J, Zhu T, Chang HS, van Loon LC, Pieterse CMJ. 2004. The

552 transcriptome of rhizobacteria-induced systemic resistance in Arabidopsis. Molecular Plant

$553 \quad$ Microbe Interactions. 17:895-908.

554 Wagner MR, Lundberg DS, Coleman-Derr D, Tringe SG, Dangl JL, Mitchell-Olds T. 2014.

555 Natural soil microbes alter flowering phenology and the intensity of selection on flowering

556 time in a wild Arabidopsis relative. Ecology Letters. 17:717-726.

557 Walker V, Bertrand C, Bellvert F, Moënne-Loccoz Y, Bally R, Comte G. 2011. Host plant

558 secondary metabolite profiling shows a complex, strain-dependent response of maize to plant

559 growth-promoting rhizobacteria of the genus Azospirillum. New Phytologist. 189:494-506.

560 Wang Y, Ohara Y, Nakayashiki H, Tosa Y, Mayama S. 2005. Microarray analysis of the gene

561 expression profile induced by the endophytic plant growth-promoting rhizobacteria,

562 Pseudomonas fluorescens FPT9601-T5 in Arabidopsis. Molecular Plant Microbe

$563 \quad$ Interactions. 18:385-396.

564 Wasternack C, Parthier B. 1997. Jasmonate-signalled plant gene expression. Trends in Plant

$565 \quad$ Science. 2: 302-307.

566 Weston DJ, Pelletier DA, Morrell-Falvey JL, Tschaplinski TJ, Jawdy SS, Lu TYS, Allen SM,

567 Melton SJ, Martin MZ, Schadt CW, Karve AA, Chen JG, Yang X, Doktycz MJ, Tuskan GA.

568 2012. Pseudomonas fluorescens induces strain-dependent and strain-independent host plant

569 responses in defense networks, primary metabolism, photosynthesis, and fitness. Molecular

$570 \quad$ Plant Microbe Interactions. 25:765-778.

571 Wright IJ, Reich, PB, Westoby M, Ackerly DD, Baruch Z. 2004. The worldwide leaf economics

$572 \quad$ spectrum. Nature. 428:821-827. 
573 Xin G, Zhang G, Kang JW, Staley JT, Doty SL. 2009. A diazotrophic, indole-3-acetic acid-

574 producing endophyte from wild cottonwood. Biology and Fertility of Soils. 45:669-674.

575 Yang J, Kloepper JW, Ryu C-M. 2009. Rhizosphere bacteria help plants tolerate abiotic stress.

576 Trends in Plant Science. 14:1-4.

577 Yang SF, Hoffman NE. 1984. Ethylene biosynthesis and its regulation in higher plants. Annual

578 Review of Plant Physiology and Plant Molecular Biology. 35:155-189.

579 Zamioudis C, Mastranesti P, Dhonukshe P, Blilou I, Pieterse CMJ. 2013. Unraveling Root

580 Developmental Programs Initiated by Beneficial Pseudomonas spp. Bacteria. Plant

$581 \quad$ Physiology. 162:304-318.

582 Zou J, Rodriguez-Zas S, Aldea M, L, M, Zhu J, Gonzalez DO, Vodkin LO, DeLucia E, Clough

583 SJ. 2005. Expression Profiling Soybean Response to Pseudomonas syringae Reveals New

584 Defense-Related Genes and Rapid HR-Specific Downregulation of Photosynthesis. Molecular

585 Plant Microbe Interactions. 18:1161-1168. 


\section{Table $\mathbf{1}$ (on next page)}

Predicted plant-interaction pathways in bacterial strains Burkholderia sp. BT03, Pseudomonas fluorescens GM30, and Pseudomonas fluorescens GM4.

Predicted plant-interaction pathways in bacterial strains Burkholderia sp. BT03, Pseudomonas fluorescens GM30, and Pseudomonas fluorescens GM41. Genome size, relevant pathways, and COG category statistics were identified using IMG tools. Where applicable, gene loci indicating predicted functions in genomes (individual genes or pathways) were included. NA $=$ not applicable. 


\begin{tabular}{llll}
\hline & Burkholderia BT03 & Pseudomonas GM30 & Pseudomonas GM41 \\
\hline Genome size (Mb) & 10.9 & 6.1 & 6.6 \\
ACC deaminase & PMI06_0002752 & PMI25_02765 & PMI27_01478 \\
salicylate metabolism & PMI06_001931 & NA & PMI27_05197 \\
auxin biosynthesis & PMI06_005275 & PMI25_03791 & PMI27_00952 \\
pili, fimbriae & PMI06_00372-3373 & PMI25_00378-0372 & NA \\
flagella & PMI06_009483-9498 & PMI25_03624-3649 & PMI27_02843-2866 \\
chemotaxis & PMI06_009463-9475 & PMI25_05665-5658 & PMI27_05395-5382 \\
type 2 secretion system & PMI06_001352-1341 & PMI25_00837-00844 & NA \\
type 3 secretion system & PMI06_000607-0617 & NA & NA \\
type 4 secretion system & PMI06_009642-9622 & NA & NA \\
type 6 secretion system & PMI06_001813-1833 & PMI25_012011220 & PMI27_02378-2397 \\
carbohydrate metabolism & & & 291 \\
$\begin{array}{l}\text { \# of genes) } \\
\text { secondary metabolite }\end{array}$ & 582 & 222 & 148 \\
\hline
\end{tabular}




\section{Table 2 (on next page)}

Colony forming units found in leaf, root, and stem tissue of Populus trichocarpa genotypes inoculated with Pseudomonas GM30, Pseudomonas GM41, or Burkholderia BT03 across three dillution factors.

Colony forming units found in leaf, root, and stem tissue of Populus trichocarpa genotypes inoculated with Pseudomonas GM30, Pseudomonas GM41, or Burkholderia BT03 across three different dilution factors: $1 \times, 0.1 \times, 0.01 \times$ concentrations of the original sample.

Pseudomonas GM41 and Burkholderia BT03 data were first published in Timm et al. (2016). 


\begin{tabular}{|c|c|c|c|c|c|c|c|c|c|}
\hline Treatment & Tissue & Dilution & mean CFU & St dev & & Sum Sq & Df & $\mathbf{F}$ & $p$ \\
\hline Control & leaf & $1.0 \mathrm{E}+01$ & 1080.5 & 1871.5 & Bact. & $1.3 \mathrm{E}+12$ & 3 & 1.24 & 0.319 \\
\hline GM30 & leaf & $1.0 \mathrm{E}+01$ & 19574.7 & 30672.7 & Tissue & $1.4 \mathrm{E}+12$ & 2 & 1.92 & 0.1699 \\
\hline GM41 & leaf & $1.0 \mathrm{E}+01$ & 1141.3 & 1809.3 & $\mathrm{~B} \times \mathrm{T}$ & $1.6 \mathrm{E}+12$ & 6 & 0.74 & 0.6264 \\
\hline ВТ03 & leaf & $1.0 \mathrm{E}+01$ & 41175.9 & 45063.1 & Resid. & $8.1 \mathrm{E}+12$ & 24 & & \\
\hline Control & root & $1.0 \mathrm{E}+01$ & 110.2 & 131.5 & & & & & \\
\hline GM30 & root & $1.0 \mathrm{E}+01$ & 170447.1 & 212977.7 & & & & & \\
\hline GM41 & root & $1.0 \mathrm{E}+01$ & 2438.9 & 1563.8 & & & & & \\
\hline ВT03 & root & $1.0 \mathrm{E}+01$ & 309628.0 & 106958.6 & & & & & \\
\hline Control & stem & $1.0 \mathrm{E}+01$ & 0.0 & 0.0 & & & & & \\
\hline GM30 & stem & $1.0 \mathrm{E}+01$ & 1166273.0 & 1872593.0 & & & & & \\
\hline GM41 & stem & $1.0 \mathrm{E}+01$ & 1510.2 & 2135.8 & & & & & \\
\hline ВТ03 & stem & $1.0 \mathrm{E}+01$ & 654513.2 & 688365.7 & & & & & \\
\hline Control & leaf & $1.0 \mathrm{E}-01$ & 1044.4 & 1809.0 & Bact. & $1.2 \mathrm{E}+13$ & 3 & 18.77 & $>0.001$ \\
\hline GM30 & leaf & $1.0 \mathrm{E}-01$ & 16643.8 & 28827.9 & Tissue & $3.8 \mathrm{E}+12$ & 2 & 9.21 & 0.001 \\
\hline GM41 & leaf & $1.0 \mathrm{E}-01$ & 566.2 & 980.7 & $\mathrm{~B} \times \mathrm{T}$ & $1.1 \mathrm{E}+13$ & 6 & 8.91 & $>0.001$ \\
\hline ВТ03 & leaf & $1.0 \mathrm{E}-01$ & 60745.9 & 54910.0 & Resid. & $5.0 \mathrm{E}+12$ & 24 & & \\
\hline Control & root & $1.0 \mathrm{E}-01$ & 402.7 & 377.6 & & & & & \\
\hline GM30 & root & $1.0 \mathrm{E}-01$ & 120591.5 & 111174.4 & & & & & \\
\hline GM41 & root & $1.0 \mathrm{E}-01$ & 2851.9 & 3319.7 & & & & & \\
\hline ВТ03 & root & $1.0 \mathrm{E}-01$ & 3096279.7 & 1069585.6 & & & & & \\
\hline Control & stem & $1.0 \mathrm{E}-01$ & 0.0 & 0.0 & & & & & \\
\hline GM30 & stem & $1.0 \mathrm{E}-01$ & 289189.7 & 330089.7 & & & & & \\
\hline GM41 & stem & $1.0 \mathrm{E}-01$ & 0.0 & 0.0 & & & & & \\
\hline
\end{tabular}




\begin{tabular}{|c|c|c|c|c|c|c|c|c|c|}
\hline BT03 & stem & $1.0 \mathrm{E}-01$ & 904314.7 & 1099508.6 & & & & & \\
\hline Control & leaf & $1.0 \mathrm{E}-02$ & 0.0 & 0.0 & Bact. & $6.9 \mathrm{E}+14$ & 3 & 13.78 & $>0.001$ \\
\hline GM30 & leaf & $1.0 \mathrm{E}-02$ & 0.0 & 0.0 & Tissue & $4.0 \mathrm{E}+14$ & 2 & 11.79 & $>0.001$ \\
\hline GM41 & leaf & $1.0 \mathrm{E}-02$ & 0.0 & 0.0 & $\mathrm{~B} \times \mathrm{T}$ & $1.2 \mathrm{E}+15$ & 6 & 11.47 & $>0.001$ \\
\hline ВТ03 & leaf & $1.0 \mathrm{E}-02$ & 73537.1 & 80004.4 & Resid. & $4.1 \mathrm{E}+14$ & 24 & & \\
\hline Control & root & $1.0 \mathrm{E}-02$ & 0.0 & 0.0 & & & & & \\
\hline GM30 & root & $1.0 \mathrm{E}-02$ & 368195.0 & 510398.0 & & & & & \\
\hline GM41 & root & $1.0 \mathrm{E}-02$ & 20595.2 & 35671.9 & & & & & \\
\hline ВТ03 & root & $1.0 \mathrm{E}-02$ & 28809015.5 & 14126689.6 & & & & & \\
\hline Control & stem & $1.0 \mathrm{E}-02$ & 0.0 & 0.0 & & & & & \\
\hline GM30 & stem & $1.0 \mathrm{E}-02$ & 227127.9 & 252544.5 & & & & & \\
\hline GM41 & stem & $1.0 \mathrm{E}-02$ & 0.0 & 0.0 & & & & & \\
\hline BT03 & stem & $1.0 \mathrm{E}-02$ & 1805855.2 & 1567125.7 & & & & & \\
\hline
\end{tabular}

2 


\section{Figure 1}

Structural traits of Populus trichocarpa that were not inoculated with bacteria (no microbe control) or were inoculated with Pseudomonas GM30, Pseudomonas GM4, or Burkholderia BT03.

Figure 1: Structural traits of Populus trichocarpa that were not inoculated with bacteria (no microbe control) $(n=8)$, were inoculated with Pseudomonas GM30 $(n=7)$, Pseudomonas GM41 ( $n=8)$, or Burkholderia BT03 $(n=7)$. a) Change in leaf number from the first to last day of the experiment. Negative values indicate that leaves senesced during the experiment. b) Leaf surface area growth rates $\left.\left(\mathrm{cm}^{2} \mathrm{~d}^{-1}\right), c\right)$ Stem growth rate $\left(\mathrm{cm}^{1} \mathrm{~d}^{-1}\right)$. d) Root surface area growth rates $\left(\mathrm{cm}^{2} \mathrm{~d}^{-1}\right)$. Letters represent significant differences of post-hoc least squares means among bacterial treatments. Boxplots display median, first and third quartiles, and vertical lines represent $1.5 \times$ inner quartile range of our dataset. The dots represent raw data values. 

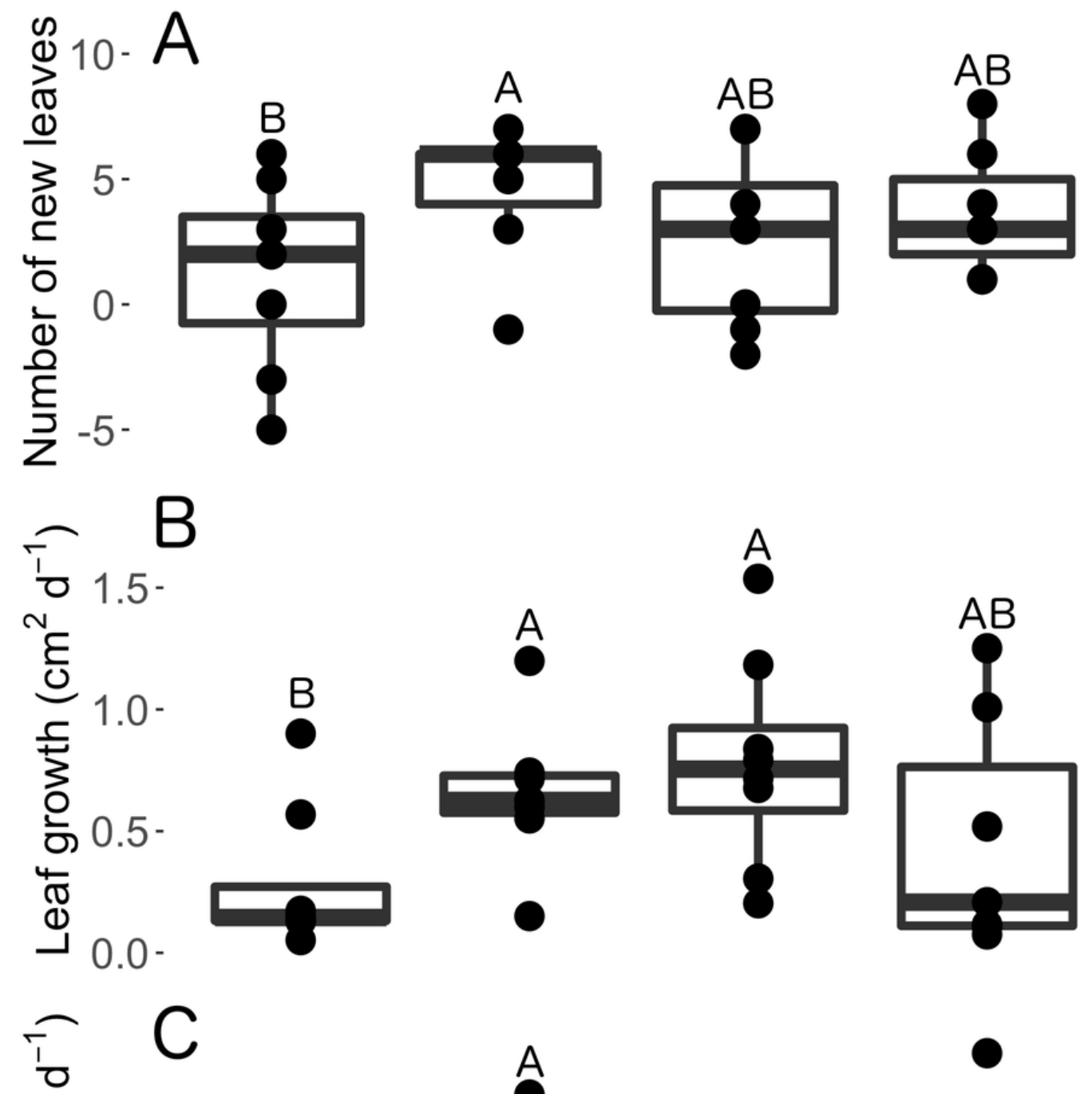

들 0.4 -
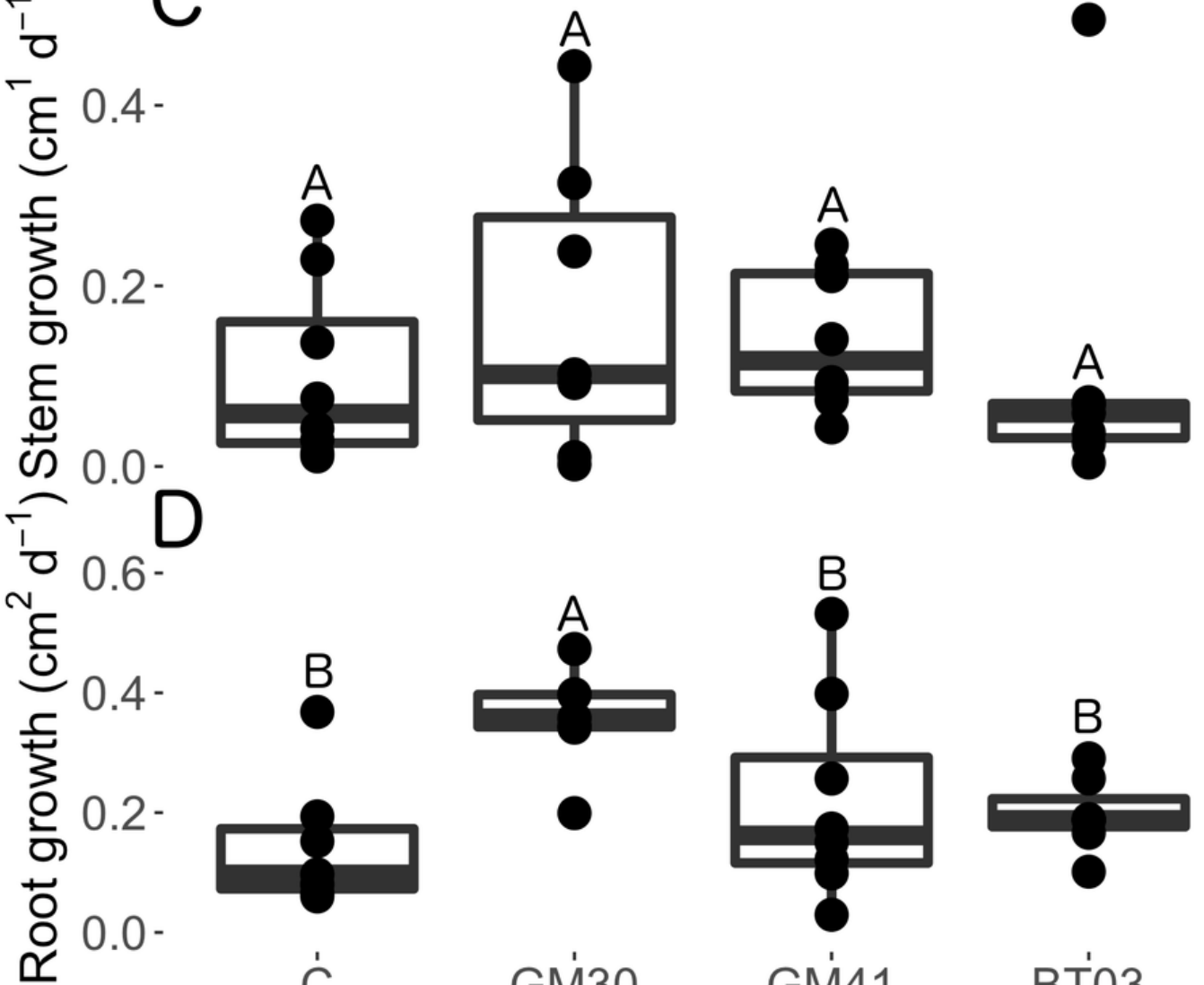


\section{Figure 2}

Biomass allocation of Populus trichocarpa that were not inoculated with bacteria (no microbe control) or were inoculated with Pseudomonas GM30, Pseudomonas GM41, or Burkholderia BT03.

Figure 2: Biomass allocation of Populus trichocarpa that were not inoculated with bacteria (no microbe control) $(n=8)$, were inoculated with Pseudomonas GM30 $(n=7)$, Pseudomonas GM41 ( $n=8)$, or Burkholderia BT03 ( $n=7)$. a) Total dry mass (mg). b) Leaf biomass (mg), c) Root biomass (mg). Letters represent significant differences of post-hoc least squares means among bacterial treatments. Boxplots display median, first and third quartiles, and vertical lines represent $1.5 \times$ inner quartile range of our dataset. The dots represent raw data values. 

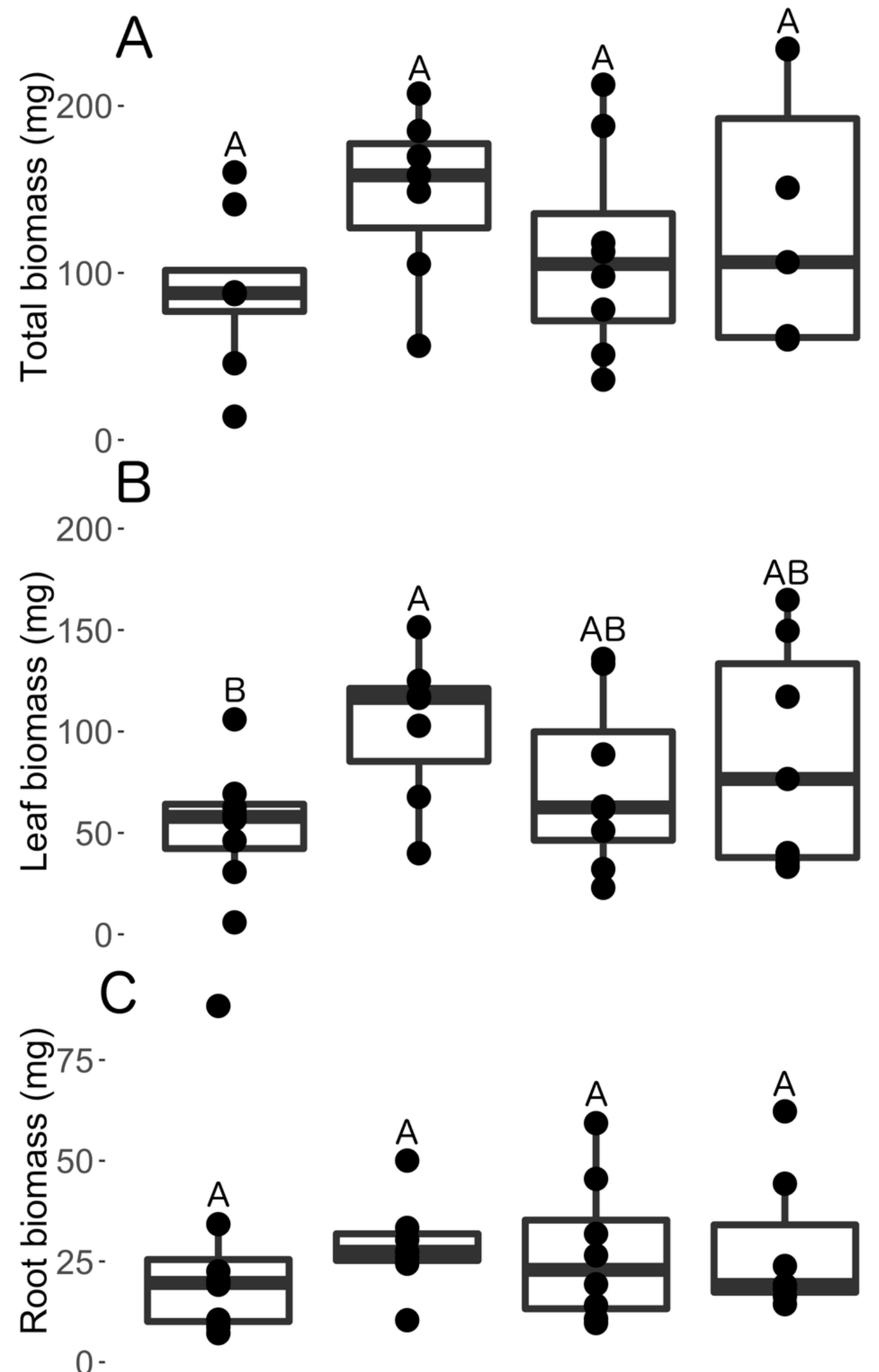

$\stackrel{\mathrm{C}}{\mathrm{C}}$

GM่30

GM่41

ВTं03 


\section{Figure 3}

Physiology traits of Populus trichocarpa that were not inoculated with bacteria (no microbe control) or were inoculated with Pseudomonas GM30, Pseudomonas GM41, or Burkholderia BT03.

Figure 3: Physiology traits of Populus trichocarpa that were not inoculated with bacteria (no microbe control) $(n=8)$, were inoculated with Pseudomonas GM30 $(n=7)$, Pseudomonas GM41 $(n=8)$, or Burkholderia BT03 $(n=7)$. a) Plant chlorophyll content (SPAD), b) $\Phi \mathrm{CO}_{2}$ (expressed as the slope of carboxylase activity across different light levels), and $\mathrm{c}$ ) carboxylase activity under maximum light level and $\mathrm{CO}_{2}$ concentration $\left(\mathrm{A}_{\max }\right)$. Letters represent significant differences of post-hoc least squares means among bacterial treatments. Boxplots display median, first and third quartiles, and vertical lines represent $1.5 \times$ inner quartile range of our dataset. The dots represent raw data values. 

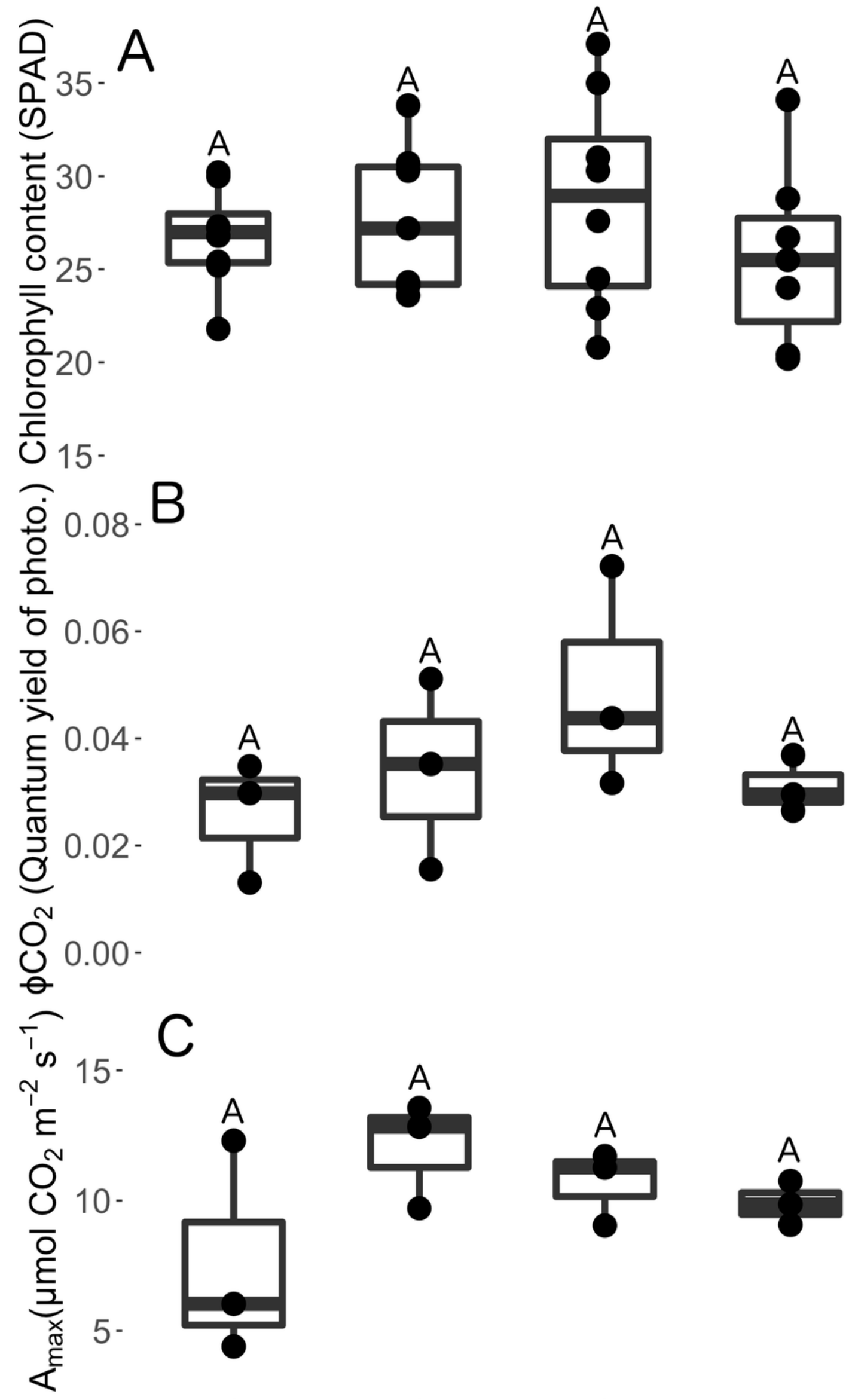

Ć GMi30 GMं41 BT'03 